\title{
Making HIV services more responsive to young children and infants in Nyanza
}

Monica Wanjiru

Population Council

Follow this and additional works at: https://knowledgecommons.popcouncil.org/departments_sbsr-rh

Part of the Demography, Population, and Ecology Commons, Family, Life Course, and Society

Commons, Health Policy Commons, Immune System Diseases Commons, International Public Health

Commons, Maternal and Child Health Commons, Medicine and Health Commons, Virus Diseases

Commons, and the Women's Health Commons

How does access to this work benefit you? Let us know!

\section{Recommended Citation}

Wanjiru, Monica. 2011. "Making HIV services more responsive to young children and infants in Nyanza," APHIA II Operations Research Project in Kenya Programme Brief. Nairobi: Population Council. 


\section{APHIA II \\ Operations Research \\ Project in Kenya}

\section{Programme Brief}

\section{Making HIV services more responsive to young children and infants in Nyanza}

Without appropriate treatment, nearly half of children born with HIV die before their second birthday. However, most primary healthcare facilities are not able to diagnose HIV infection in children because the rapid HIV antibody tests commonly used are not applicable to children younger than 18 months. In addition, clinical features of infection are too unspecific in children to be of any benefit in aiding diagnosis of HIV infection.

The availability of DNA-PCR (polymerase chain reaction) testing has made it possible to detect HIV infection in infants as young as six weeks old, using capillary blood obtained from infants using the heelprick method. Although the technology is only available to a few laboratories in Kenya, with good training in sample collection and storage, health staff can collect Dry Blood Spots (DBS) from peripheral sites and deliver them to a laboratory where DNA-PCR tests are available.

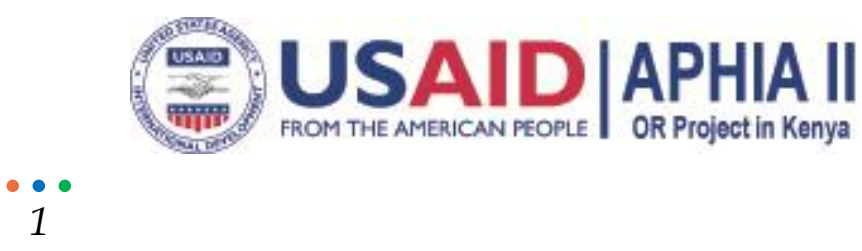


However, parents and caregivers are not always aware of these services, nor are they always able to access them for infants and children. A study published in 2008 by Population Council/Horizons Project (Kiragu et al, 2008) found several barriers that impede children's access to early diagnosis and treatment. These include caregivers' poor knowledge regarding availability of paediatric HIV services and early diagnosis; stigma surrounding HIV infection; and poor health worker attitudes and delays at the clinic in obtaining services. Health workers also often missed opportunities to discuss paediatric HIV with clients and to track exposed children in order to initiate treatment.

To address this problem, APHIA II Operations Research (OR) Project collaborated with the Christian Health Association of Kenya (CHAK), Catholic Relief Services (CRS) and the Kendu Adventist Hospital (KAH) to improve HIV testing and treatment services for children at the hospital. KAH is a 100-bed mission hospital located in Nyanza Province. The hospital serves a large area, and its Comprehensive Care Centre (CCC) provides much needed services for people living with HIV in the area.

Barriers impeding access to HIV services for young children and infants

Research has shown that the following factors impede parents' and care-givers' ability to access HIV testing and treatment services for their children and infants:

- Lack of money to pay for transport to facility and for some health services.

- Caregivers' preference for traditional healers as a first point of contact for health care.

- Caregivers' poor knowledge of HIV in children in general.

- Caregivers' limited knowledge of early infant diagnosis of HIV and treatment, and where these services are available.

- Fear of stigma around HIV

- Poor attitudes among health workers

- Lack of child-friendly services, and long delays at the clinic

Source: Karusa Kiragu, Katie Schenk, Julie Murugi and Avina Sarna. 2008. "Ifyou build it, will they come?" Kenya Healthy Start Paediatric HIV study: A diagnostic study investigating barriers to HIV treatment and care among children. Horizons Population Council

\section{The interventions}

Two sets of activities were implemented under this pilot project: improving HIV testing and treatment services for children at the hospital, and increasing awareness of HIV services for children in the local community.

\section{I: Improving HIV testing and Treatment services for children at KAH}

A preliminary assessment conducted at Kendu Adventist Hospital showed that the different units concerned with the care of exposed infants (antenatal, maternity, well-baby clinics and the comprehensive care centre) were poorly linked, which impeded the identification and follow-up of infants exposed to HIV, and their 
linkage to early infant diagnosis of HIV and appropriate treatment. To rectify this, the following changes were put in place:

Improved case tracking: To ensure that exposed children were tested and enrolled for care and treatment as soon as possible, a staff member (nurse) was assigned to review clinic records and the Mother-Baby card developed by the Ministry of Health, to identify children born to mothers living with HIV who had received PMTCT services at the hospital, and to give them referral to the laboratory for HIV testing as soon as they were six weeks old. In addition, mothers living with HIV who came to deliver at the hospital were given counselling and encouraged to bring back the baby for HIV testing and routine childhood immunization at 6 weeks. Staff also assessed sick children receiving services in the Outpatient Department and offered HIV testing if they suspected that the child was exposed to HIV.

\section{Linkages strengthened between maternity, child health and CCC: The} facility assessment showed that there was little integration between the various units involved in the care of HIV-exposed infants - the MCH clinic, where PMTCT and child immunizations are provided, maternity, and the CCC. A referral system was put in place between these units, which included referral slips, feedback system, new registers and development of standard operating procedures. The registers were used to generate service delivery statistics at every point to monitor access and identify where clients dropped out of the system and to rectify that. To enhance the monitoring of the system, meetings were held regularly between the three departments to compare experiences and review progress. Standard Operation Procedures (SOPs) were developed to guide referral processes between the different units, and reminding staff about how to handle exposed infants. As per WHO guidelines, all HIV-exposed infants were put on Cotrimoxazole (Septrin) from 4-6 weeks to prevent opportunistic infections, until the results of their HIV test were received, when it was discontinued if they were found to be HIVfree.

Improved feedback on HIV test results to KAH laboratory: During the OR study, Kendu Adventist Hospital did not have equipment for DNA/PCR tests used for early infant diagnosis of HIV. Dry blood samples (DBS) were sent to an offsite laboratory at CDC /KEMRI in Kisumu, but getting back the results would sometimes take up to a month, and in the process, some results were lost. This discouraged parents and caregivers, who often had to make several trips to the hospital to check for the results or have the child re-tested. 
Following negotiations with CDC/KEMRI, it was agreed that the laboratory would henceforth send back results to the KAH through email to speed up the process. This vastly improved record keeping and tracking of samples and test results as well as the time it took between collection of blood sample and commencement of treatment for infected children.

More child-friendly services: The Comprehensive Care Centre at Kendu Adventist Hospital provides paediatric ART services alongside those for adults. However, the facility assessment showed that due to a heavy client load on most days, clients often spent long hours waiting for services. This waiting period was found to be especially hard for parents and caregivers of young children, and sometimes some gave up waiting and went home with the child unattended. To address this problem, the hospital set aside one day (Sunday) in the week, when only children and the adult accompanying them would be attended to at the CCC. The centre was also made more childfriendly by providing toys and crafts for the young clients.

Additional staff: The preliminary assessment found that there was high demand for services at the hospital's Comprehensive Care Centre (CCC), the Maternal Child Health and out-patient department. However, the hospital did not have adequate numbers of staff. Two new staff, a nurse and a laboratory technician, were hired to support the paediatric HIV/AIDS services.

\section{II: Increasing awareness of paediatric HIV services in the community}

To address the caregivers' poor knowledge regarding paediatric HIV services and early diagnosis, and the fear of stigma surrounding HIV infection, the following activities were implemented:

Awareness campaign: Communication activities were implemented by community health workers and volunteers from the Kendu Adventist Health Services in the community to increase awareness of the availability of HIV services for children and early infant diagnosis. The key messages focused on educating the community about the availability of HIV testing and treatment services for children and where they could be found, and the general care for a child/infant living with HIV. They also emphasised the need for pregnant women to attend ANC services and to deliver at health facilities. These messages were disseminated through leaflets and brochures, and during community outreach activities by teams from the hospital. Pastoral staff from 
the Kendu Adventist Church also used religious events to disseminate the messages. During the project period, 1600 brochures were distributed in the community in Kendu District. Mothers living with HIV also received support in the community through visits by volunteer health workers and were encouraged to form support groups with other mothers.

Community Outreach: Kendu Adventist Hospital regularly conducts community outreach activities, where $\mathrm{MCH}$ services are offered in the field, alongside community education. To meet the needs of parents who could not make the trip to the hospital, the hospital incorporated the collection of dry blood samples from infants in the outreach activities, and a laboratory technician joined the teams to perform this task. All the samples collected were submitted to the testing laboratory.

\section{Achievements}

\section{Improvement in service uptake}

Significant improvements were found in service uptake during the project period:

The number of exposed children who were traced and tested for HIV at KAH rose from an average of 28 infants to 54 per month within a six-month period (July-December 2010).

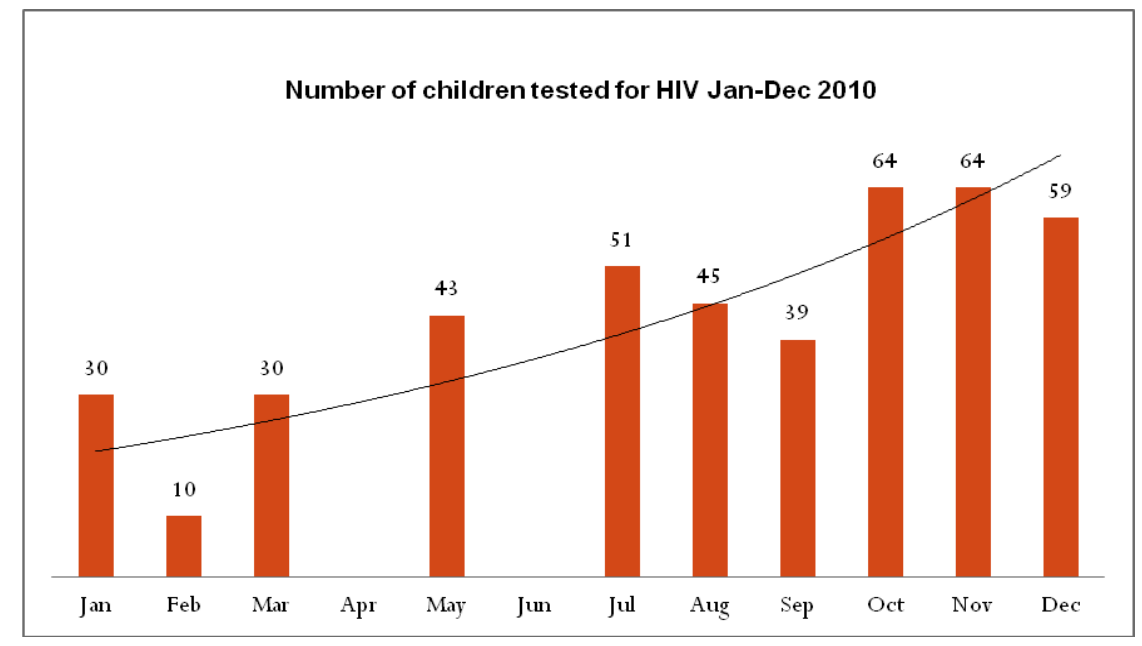

184 exposed children were started on Cotrimoxazole (Septrin) to prevent opportunistic infections in the same period, compared to 109 a year earlier. A further $72 \mathrm{HIV}$-positive children were started on ARVs in the six-month period, compared to 35 in the same period in 2009. 


\section{Improvements in knowledge and attitudes regarding HIV in children:}

More community members aware of mother-to-child transmission and how to prevent it: When the intervention was evaluated, $14 \%$ of the respondents correctly cited pregnancy as means of mother-to-child transmission (MTCT) of HIV, compared to only $6 \%$ at baseline, while $20 \%$ knew of childbirth as a means of MTCT at endline, compared to $13 \%$ at baseline.

Positive attitudes towards HIV testing in children: The intervention appears to have improved people's willingness to take an exposed child for treatment. The proportion of those willing to take a child for treatment if they suspected he/she was HIV-infected rose significantly from $18 \%$ at baseline to $30 \%$ at endline. Increases were also found in the proportion of respondents who agreed that siblings of an HIV-infected child should also be tested for HIV. About half of the respondents (49\%) knew that HIV testing, treatment and care services for children are free, compared to $28 \%$ at baseline. The proportion of respondents whose child under 15 years had ever been tested for HIV rose from $24 \%$ at baseline to $35 \%$ at endline.

More willingness to care for HIV-infected child: There was an increase in the proportion of respondents willing to take care of a child living with HIV, from $89 \%$ to $99 \%$ by the end of the intervention. Similarly, $98 \%$ of the respondents were willing to let a child living with HIV go to school in the endline survey, compared to $89 \%$ at baseline.

Less time spent before receiving services at health facility: The reorganization of services at KAH reduced the time that clients spent waiting for services at the facility, and the number of service providers the client had to see on a single visit. The total time spent at the facility reduced from a median of two and a half hours at baseline to 68 minutes at endline. The average number of service providers seen by one client during one visit also dropped to four from seven.

\section{Critical gaps persist that should be addressed}

Decreasing counselling on HIV testing: The evaluation found a reduction in the proportion of clients reporting having received counselling about HIV testing for their child on the day of the interview, from $33 \%$ at baseline to $22 \%$ at endline. This finding is corroborated by evidence from observations, where decreases were also found in the proportion of sessions where counselling on HIV testing was given, from $43 \%$ at baseline to $24 \%$ at endline.

Poor knowledge of early infant diagnosis: Knowledge about early infant diagnosis was found to be low in the evaluation, and only $22 \%$ of the respondents at endline knew that testing for HIV can be done at six weeks after birth. 
Poor knowledge of MTCT: Although knowledge improved regarding mother-tochild transmission of HIV through pregnancy and child-birth, it is still quite low. There was also not much improvement in knowledge about transmission through breast-feeding: only $24 \%$ of the respondents at the evaluation/endline knew that breast-feeding could transmit HIV infection, compared to $23 \%$ at baseline.

\section{Utilization of findings}

Kendu Adventist Hospital used the intervention activities to strengthen its operations. The hospital has continued to set aside one day a week, when infants, young children and teenagers can receive focused HIV care. The hospital also continues to use the standard operation procedures to ensure optimal care in managing exposed infants. Record keeping and tracking of DBS samples and PCR test results by the KAH laboratory has continued.

\section{Conclusions}

Paediatric HIV services should be strengthened and included as an essential service at all levels of healthcare facilities to reach more children, and could even be included as one of the roles of the community health workers. It should also be included in training and guidelines for providers with emphasis on identifying gaps in client flow within health systems. Laboratory services should be streamlined to ensure optimal management of DBS samples and record-keeping.

The Ministry of Health and APHIA plus should also consider replicating the model of service delivery used in this OR study in other facilities in the province, to ensure that continuum of care is maintained from ANC to Well-Baby and CCC clinics.

This study was funded the United States Agency for International Development (USAID) under the terms of cooperative agreement No. 623-A-00-09-00001-00, (APHIA II OR Project) with Population Council. The contents of this publication are the responsibility of the Population Council and do not necessarily reflect the views of USAID or the United States Government.

Source: Kalibala, S, S Kiplangat, S Sarna, and R Mwangi. 2011. Enhancing Uptake of Paediatric HIV Testing and Treatment in Kenya: Intervention Study Report. Population Council, Nairobi

Population Council | General Accident House || Ralph Bunche Road I| PO Box 17643-00500, Nairobi, Kenya | Tel: +254 20217 3480/1/2/3 | Fax: +254 202173479 | www.popcouncil.org

(C) 2011 The Population Council Inc Written by Monica Wanjiru

For more information, contact skalibala@popcouncil.org

\section{(P) Population Council}

